\title{
Development and Testing of a Bubble Bi-Level Positive Airway Pressure System
}

\author{
Stephen C John, Joseph D Barnett, Nickolas D Habben, Hoa T Le, Eric Cheng RRT, \\ Sunil P John MD, and Peter A Gustafson PhD
}

\begin{abstract}
BACKGROUND: Neonatal respiratory distress results in $>1$ million annual deaths worldwide. Bubble CPAP is a simple, effective, and widely used therapy for infants in respiratory distress. In low-resource settings, more advanced respiratory support is limited by cost, technical expertise, and sporadic electricity. We sought to develop a safe, inexpensive, and simple solution to provide further respiratory support for these infants. METHODS: A standard bubble CPAP system was modified to provide 2 levels of positive airway pressure (bi-level positive airway pressure) by attaching a novel device. To demonstrate reliability, the system was run with continuous pressure monitoring on full-term and preterm neonatal mannikins with pressure targets of $8 / 5 \mathrm{~cm} \mathrm{H}_{2} \mathrm{O}$ and $15 / 5 \mathrm{~cm} \mathrm{H}_{2} \mathrm{O}$ to simulate 2 different modes of noninvasive ventilation (NIV). RESULTS: At a ventilation rate set between 30 and 45 cycles/min, by adjusting the leak rate of the device, the following mean pressures \pm SD were demonstrated: term mannikin low-pressure $\mathrm{NIV}, 7.9 \pm 0.2 / 5.3 \pm 0.2 \mathrm{~cm} \mathrm{H} \mathrm{H}_{2} \mathrm{O}$; term mannikin high-pressure $\mathrm{NIV}, 15.1 \pm 0.1 / 6.1 \pm 0.1 \mathrm{~cm} \mathrm{H} \mathrm{H}_{2} \mathrm{O}$; preterm mannikin low-pressure $\mathrm{NIV}, 7.9 \pm 0.2 / 5.3 \pm 0.2 \mathrm{~cm} \mathrm{H}_{2} \mathrm{O}$; preterm mannikin high-pressure NIV, $16.5 \pm 0.4 / 5.1 \pm 0.1 \mathrm{~cm} \mathrm{H_{2 }}$ O. CONCLUSIONS: The modified bubble CPAP system reliably provided alternating pressures similar to bi-level positive airway pressure modes of respiratory support in neonatal mannikins. The dual-pressure technology is a simple, single connection add-on that can readily be applied to existing bubble CPAP systems. Key words: noninvasive ventilation; neonate; international medicine; biomedical engineering. [Respir Care 2017;62(9):1131-1136. (C) 2017 Daedalus Enterprises]
\end{abstract}

\section{Introduction}

Infant respiratory distress is a significant problem worldwide. Over 1 million neonates die each year due to respiratory causes. ${ }^{1}$ One contributing factor to the large infant

\footnotetext{
Mr John is affiliated with the University of Michigan Medical School, Ann Arbor, Michigan. Mr Barnett, Mr Habben, Mr Le, and Dr Gustafson are affiliated with Western Michigan University, Kalamazoo, Michigan. Mr Cheng is affiliated with Respiratory Therapists Without Borders, Toronto, Ontario, Canada. Dr John is affiliated with the CS Mott Children's Hospital, Ann Arbor, Michigan.

All phases of this study were supported by Venture Well (previously known as National Collegiate Inventors and Innovators Alliance) an E-teams stage 2 grant. Dr Gustafson, Mr Barnett, and Mr John have disclosed a relationship with Advanced Innovative Medical Technologies. Mr Cheng has disclosed relationships with ResMed and DeVilbiss. Dr Gustafson, Mr Barnett, Mr John, and Mr Le have filed PCT patent application WO 2016/115465 A1 for the technology described in this article. The other authors have disclosed no conflicts of interest.
}

mortality from respiratory distress is lack of access to supportive respiratory therapies. Although intensive care and mechanical ventilation have been widely adopted in some countries, these solutions remain out of the reach of many resource-limited settings.

Bubble CPAP is a safe, effective, and low-cost therapy $^{2}$ used around the world to treat infants with mildto-moderate respiratory distress. ${ }^{3-5}$ Unfortunately, other more advanced forms of noninvasive respiratory support, such as bi-level positive airway pressure (BPAP) and noninvasive ventilation (NIV) currently require mechanical ventilators or dedicated BPAP machines, neither of which are readily available in resource-limited settings. ${ }^{6}$

Correspondence: Stephen John, University of Michigan Medical School, 1301 Catherine, Ann Arbor, MI 48109-5624. E-mail: scjres@ gmail.com.

DOI: $10.4187 /$ respcare. 05443 


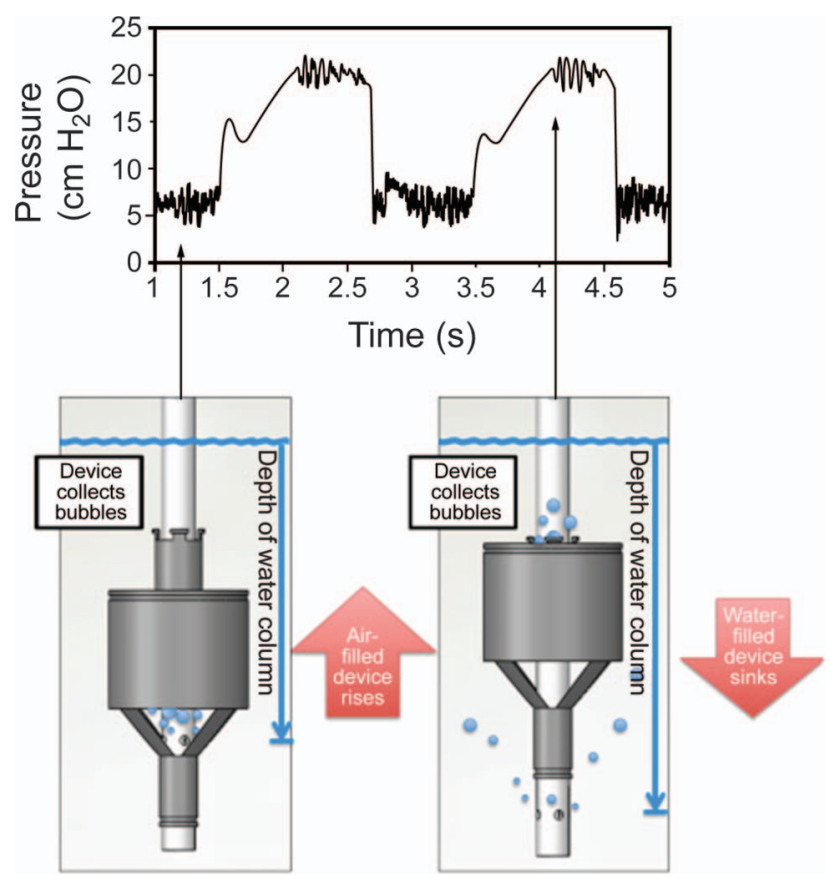

Fig. 1. Bi-level device function diagram with corresponding pressure output. Courtesy Advanced Innovative Medical Technologies.

We developed a device that delivers pressure-limited time-cycled ventilation while maintaining the low cost and simplicity of bubble CPAP. Our hypothesis was that this dual-pressure technology could reliably deliver pressures

\section{See the Related Editorial on Page 1226}

similar to conventional NIV and BPAP therapies. To test this hypothesis, we utilized a modified bubble CPAP circuit, which was attached to intubated preterm and fullterm infant mannikins.

\section{Methods}

The device incorporates 2 openings for the release of pressure at 2 separate levels on a submerged bubble CPAP pipe. A basket and its attached sleeve cyclically move vertically on the pipe, which causes the sleeve to alternately occlude the proximal and distal openings (Fig. 1). This single moving part is powered by the exhaust bubbles of bubble CPAP and thus requires no electrical power. The buoyant force of the bubbles moves the device upward. At the upper position, the device occludes the holes so that no further bubbles emerge. Also, at the upper position, the device vents the bubbles, and the float loses buoyancy. This causes the device to sink back to the lower position, and the cycle repeats itself. The clinician is able to select the upper and lower pressures by adjusting the depth of the

\section{QUICK LOOK}

\section{Current knowledge}

Bubble CPAP is an established therapy for infants with respiratory distress. Although bubble CPAP is effective for many infants, those with moderately severe respiratory distress may require additional respiratory support, which is unavailable in many resource-limited settings.

\section{What this paper contributes to our knowledge}

We describe infant mannikin testing of a novel, lowcost, low-tech device, which modifies bubble CPAP to provide 2 alternating levels of pressure similar to pressurelimited time-cycled mechanical ventilation. The system was capable of simulating bi-level airway pressure in term and preterm infant mannikin models.

distal and proximal holes under water. With the current iteration of the device, the time at the higher pressure is fixed, whereas the time at the lower pressure can be varied by adjusting the total cycle time (effectively adjusting the rate). The total cycle time is set by adjusting an in-line needle valve, which adjusts the air flow to the device. This air flow determines the amount of time required to complete one low-to-high-pressure cycle. In this way, the number of breaths/min can also be adjusted.

The basket and cylinder were fabricated using an Objet500 Connex3 (Stratasys, Eden Prairie, Minnesota) 3D printer and Vero rigid opaque material. Clear PVC one quarter-inch schedule 80 pipe was used with an inner diameter of $6.35 \mathrm{~mm}$ and outer diameter of $13.7 \mathrm{~mm}$. Weights for the device were created from 30-mm diameter stainless steel bar stock. Number 10 O-rings (Danco, Irving, Texas) were used for the lower stop material and to hold the weight onto the inverted basket. A Legris $6.35-\mathrm{mm}$ flow regulator was utilized for the inline valve.

A schematic diagram of the experimental setup is shown in Figure 2. The respiratory circuit with the dual-pressure device connected to an infant mannikin is shown in Figure 3. A full-term infant mannikin (SimNewB, Laerdal, Wappingers Falls, New York) was intubated with a $3.5-\mathrm{cm}$ double-lumen endotracheal tube, and a preterm neonatal mannikin (Premature Anne, Laerdal, Wappingers Falls, New York) was intubated with a $2.5-\mathrm{cm}$ double lumen endotracheal tube. The mannikins were intubated to create a leak-free system in which proximal airway pressure was continuously measured. The expiratory limb of a conventional bubble CPAP system was connected to the dualpressure device.

The system was run in a mode similar to BPAP with a high pressure target of $8 \mathrm{~cm} \mathrm{H}_{2} \mathrm{O}$ and a low pressure target of 


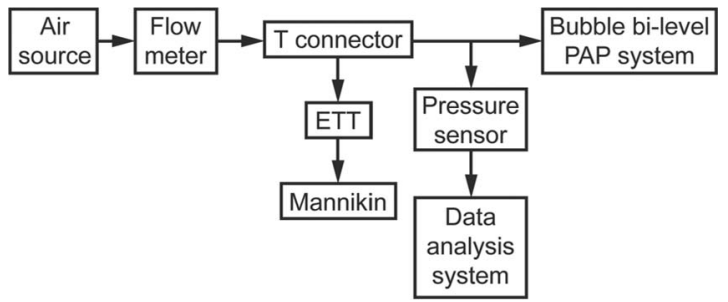

Fig. 2. Schematic diagram of experimental setup.

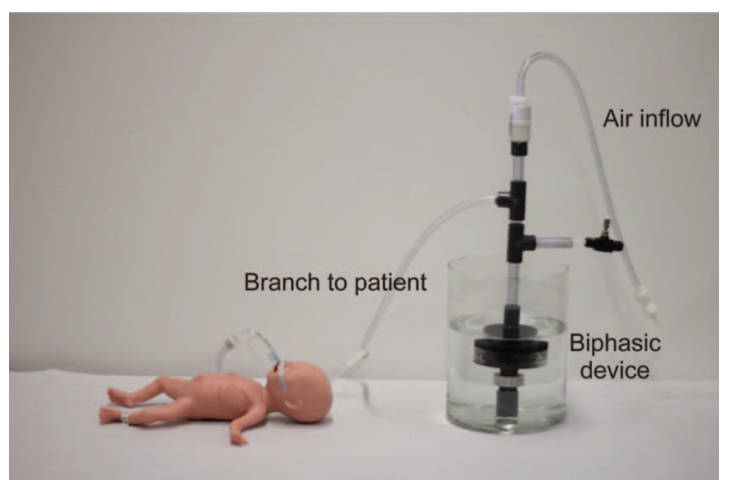

Fig. 3. Preterm neonatal mannikin (Premature Anne, Laerdal) connected to bi-level device.

$5 \mathrm{~cm} \mathrm{H}_{2} \mathrm{O}$ pressure targets for approximately $48 \mathrm{~h}$ on each mannikin. The system was subsequently run in a mode similar to NIV with a high-pressure target of $15 \mathrm{~cm} \mathrm{H}_{2} \mathrm{O}$ and a low-pressure target of $5 \mathrm{~cm} \mathrm{H}_{2} \mathrm{O}$ for approximately $5 \mathrm{~h}$ on each mannikin. In each case, the pressure levels were set by the submerged depth of the exhaust holes. The device was housed in a lidless transparent glass container, filled with distilled water. This complete sequence of BPAP mode and NIV mode testing was conducted with both the full-term and preterm mannikins.

The air source was laboratory compressed room air piped from a centrally located industrial air compressor and humidifier. Flexible $9.525-\mathrm{mm}$ nylon tubing connected the air source to a medical grade flow meter (model 1MFA, Precision Medical, Northampton, Pennsylvania) and was subsequently plumbed into the PVC pipe and the device through 6.35-mm nylon tubing. Pressure was monitored and recorded using a pressure transducer (Honeywell 162PC01D) into a data acquisition module (NI USB-6009 DAQ) connected to a computer running LabVIEW 7.1 (National Instruments Corp, Austin, Texas). The sampling rate was $200 \mathrm{~Hz}$. All data were post-processed using Octave 4.0.1 (octave.org).

Custom code was utilized within Octave to compute the mathematical mean of pressures over each cycle, based on recorded high and low levels of pressure. This would correspond to the mean airway pressure if the device were in clinical use.

\section{Results}

All numeric results listed below are reported as mean $\pm \mathrm{SD}$. Before mannikin testing, device reliability was tested by attaching the BPAP device to the expiratory limb of a bubble CPAP circuit connected to a continuous source of air pressure. With the high pressure set to $8 \mathrm{~cm} \mathrm{H}_{2} \mathrm{O}$ and low pressure to $6 \mathrm{~cm} \mathrm{H}_{2} \mathrm{O}$, the device cycled continuously between high and low pressures for 1 month without interruption.

The BPAP device was then tested by connecting the circuit to intubated preterm and full-term infant mannikins and continuously recording the pressure in the circuit. The preterm mannikin was tested for $48 \mathrm{~h}$ in a low-pressure cycling mode with target pressures (similar to ventilator BPAP) of $8 / 5 \mathrm{~cm} \mathrm{H}_{2} \mathrm{O}$. The pressure cycled between $7.9 \pm 0.2$ and $5.3 \pm 0.2 \mathrm{~cm} \mathrm{H}_{2} \mathrm{O}$ with $41 \pm 1.6$ cycles $/ \mathrm{min}$. The full-term mannikin was tested with target pressures of $8 / 5 \mathrm{~cm} \mathrm{H}_{2} \mathrm{O}$ in the same way for $48 \mathrm{~h}$. The pressure cycled between $7.9 \pm 0.2$ and $5.3 \pm 0.2 \mathrm{~cm} \mathrm{H}_{2} \mathrm{O}$ with $42.5 \pm 1.8$ cycles $/ \mathrm{min}$.

Figure 4 depicts a graphic summary of the high pressure, low pressure, and mean airway pressure over time to the preterm mannikin. In this figure, a histogram which details the distribution of the measured values is also provided to the right of the plot.

The preterm mannikin was tested for $5 \mathrm{~h}$ in a highpressure cycling mode, with target pressures (similar to the typical settings used in NIV) of $15 / 5 \mathrm{~cm} \mathrm{H}_{2} \mathrm{O}$. The pressure cycled between $16.5 \pm 0.4$ and $5.1 \pm 0.1 \mathrm{~cm} \mathrm{H}_{2} \mathrm{O}$ with $35.3 \pm 2.5 \mathrm{cycles} / \mathrm{min}$. Similarly, the full-term mannikin was tested for $5 \mathrm{~h}$ with the target pressures of $15 / 5 \mathrm{~cm} \mathrm{H}_{2} \mathrm{O}$. The pressure cycled between $15.1 \pm 0.10$ and $6.1 \pm 0.1 \mathrm{~cm} \mathrm{H}_{2} \mathrm{O}$ with $44.8 \pm 2.6 \mathrm{cycles} / \mathrm{min}$. Figure 5 provides a summary of pressures delivered over time to the preterm mannikin. Representative pressure waveforms in high- and low-pressure cycling modes during the test period are shown in Figures 6 and 7 , respectively.

\section{Discussion}

\section{Background}

Bubble CPAP is a simple and low cost mechanism for delivering CPAP. In many low-resource settings, it is the only available treatment for infants in respiratory distress, because treatment with BPAP, NIV, or mechanical ventilation is unaffordable. In these countries, a survival rate of $70 \%$ has been recorded with bubble CPAP equipment ${ }^{7}$; the remaining 30\% die for lack of additional respiratory support. There is an urgent need for affordable and simpleto-use ventilation technologies. 

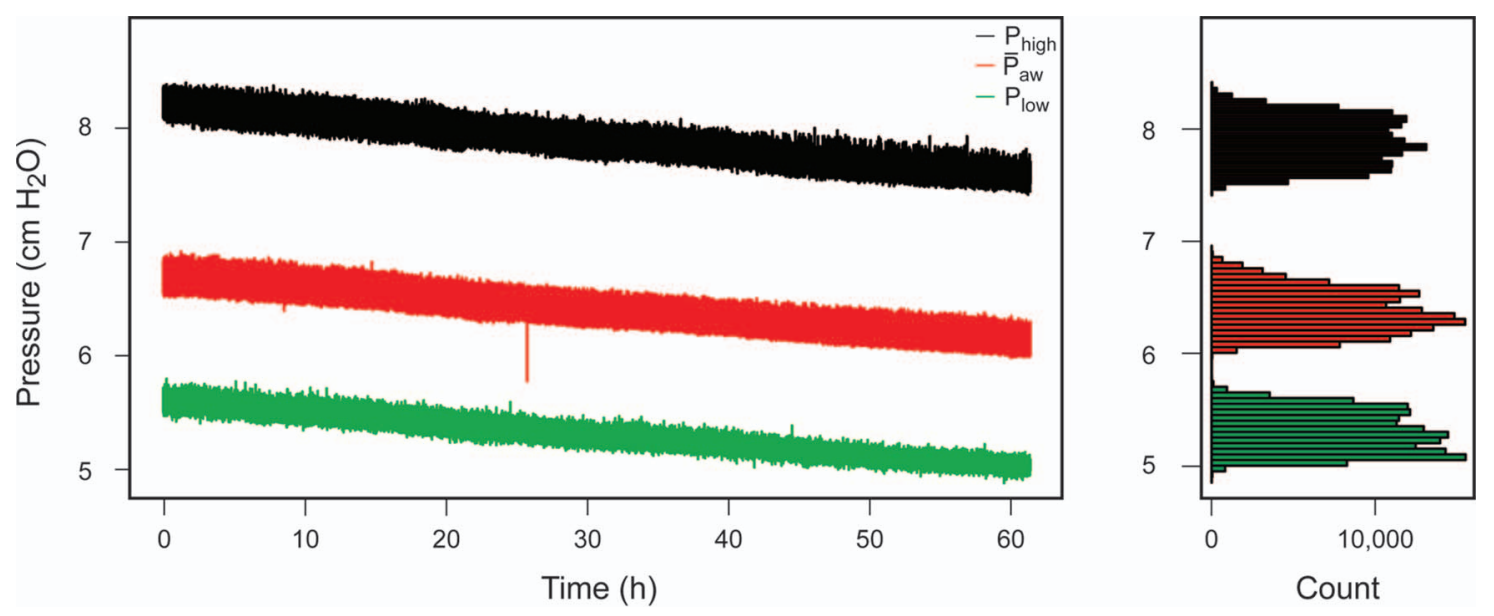

Fig. 4. Preterm mannikin low-pressure cycling: airway pressure over time with histogram showing distribution of the measured values.
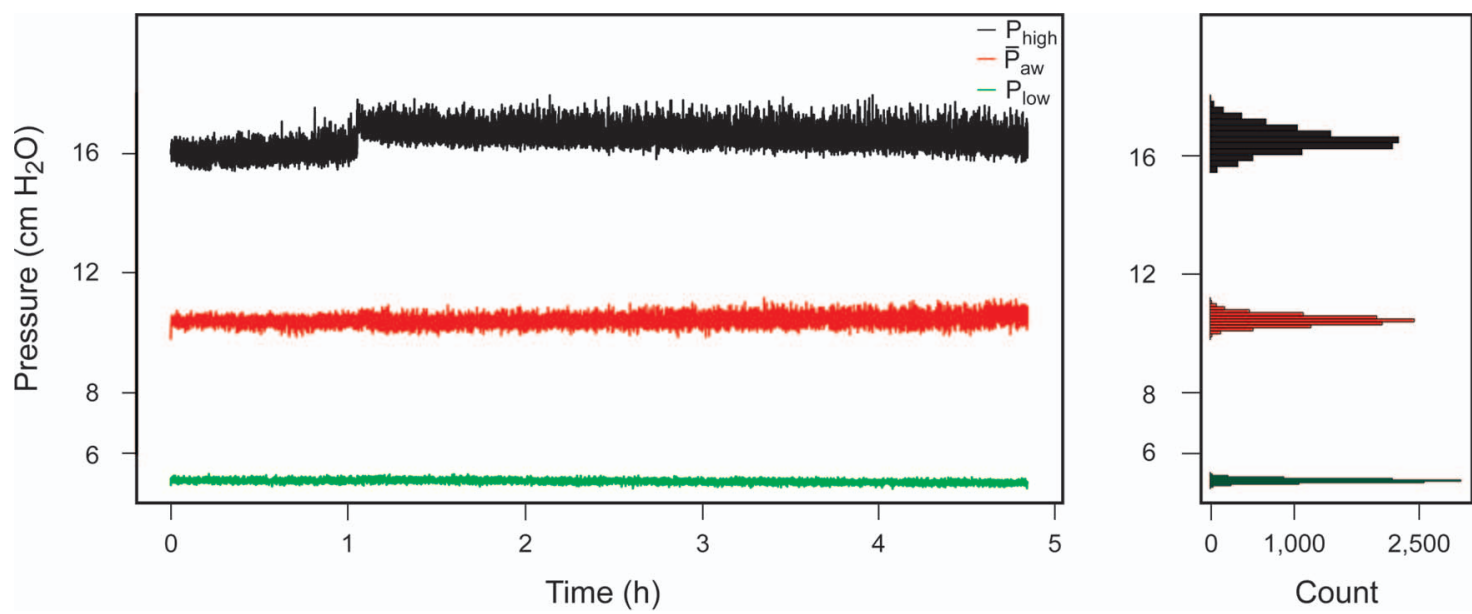

Fig. 5. Preterm manikin high-pressure cycling: airway pressure over time with histogram showing distribution of the measured values.

\section{Function}

Bubble CPAP allows consistent delivery of one level of pressure as long as a continuous source of compressed air is provided to the circuit. The device under study must deliver 2 levels of pressure with similar reliability. This study demonstrates that 2 levels of airway pressure are consistently delivered using a novel device that modifies bubble CPAP, without interruptions in cycling at the high or low pressure levels. The device was able to match BPAP and NIV pressure targets with an SD $\leq 10 \%$ of the target pressure level. Both upper and lower pressure levels were independently adjustable. The rate of ventilation was also adjustable.

Figures 4 summarizes the high pressure, low pressure, and mean airway pressure in BPAP mode over time in the preterm mannikin. The plot demonstrates that in the low pressure cycling mode, the device was found to provide consistent cycling between the targeted high and low pressures with minimal variation over $60 \mathrm{~h}$. The graph shows that pressure gradually decreased at a rate of approximately $0.5 \mathrm{~cm} \mathrm{H}_{2} \mathrm{O}$ over $60 \mathrm{~h}$. This was due to evaporation of water, because the experimental setup was not heated and humidified and did not have a lid or mechanism to prevent evaporation. We measured a comparable decrease in pressure over time in all our tests, which is to be expected, since all were performed in the same environment with the same surface area of water exposed to the environment. In clinical practice, these effects can be greatly reduced by covering the water container and using a small opening to vent air. Figure 5 summarizes the high pressure, low pressure, and mean airway pressure in NIV mode over time in the preterm mannikin.

The pressure waveforms in Figures 6 and 7 show the characteristic high-frequency oscillations caused by bubbling at both high and low pressures. These oscillations may further facilitate gas exchange at the level of the alveoli, ${ }^{8}$ providing a benefit that is currently not available with other modes of pressure ventilation. 


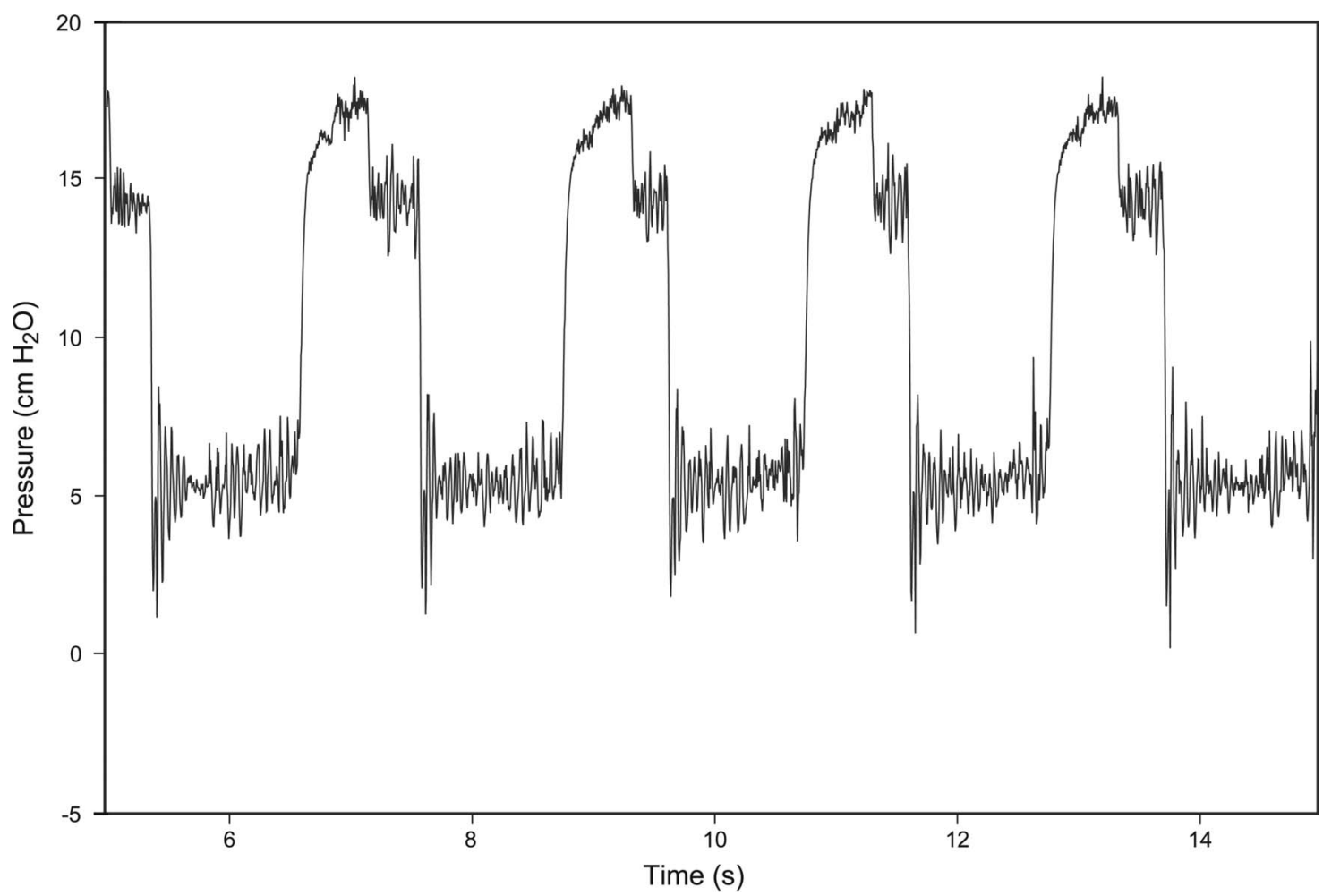

Fig. 6. Representative pressure waveforms in high-pressure cycling modes during the test period.

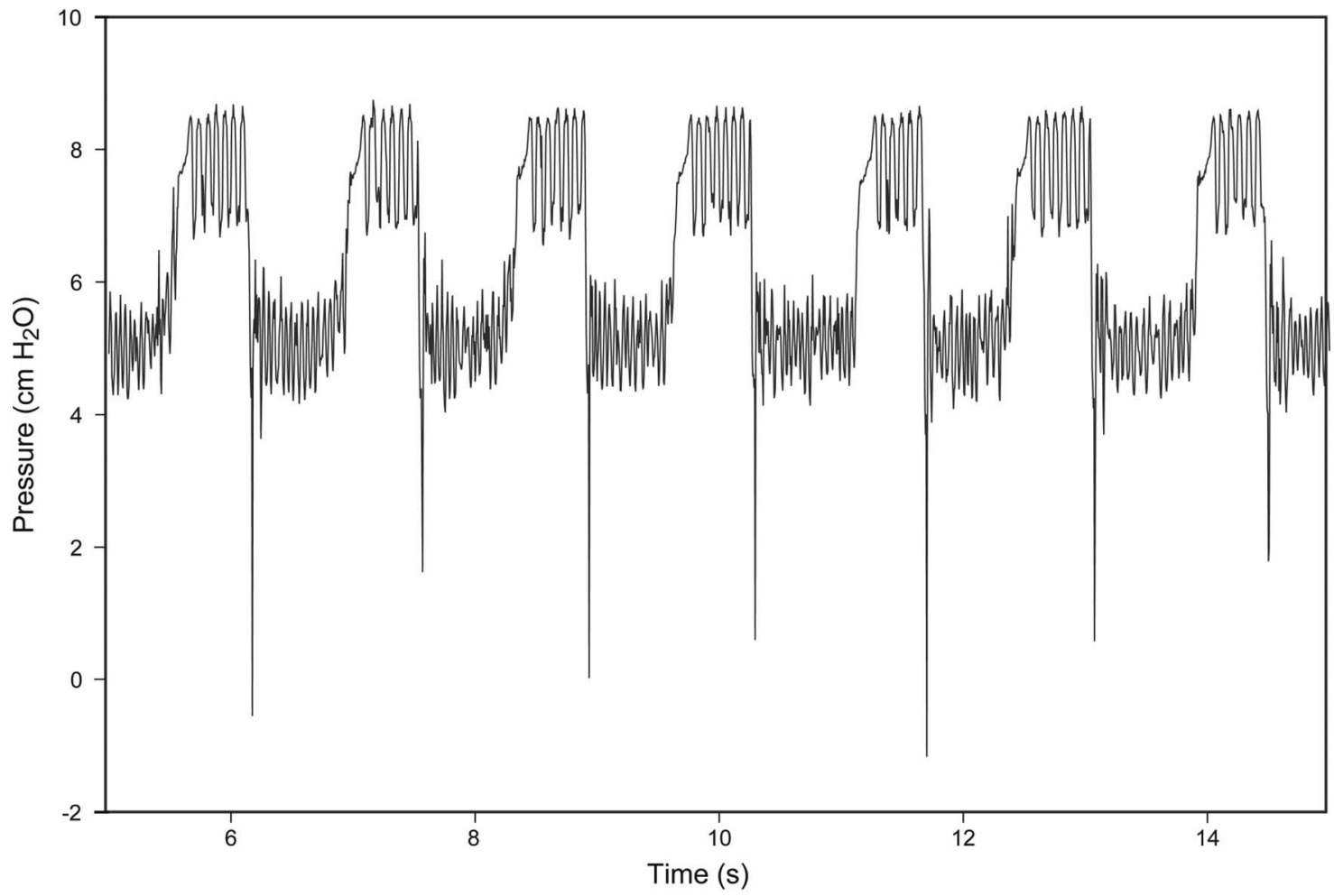

Fig. 7. Representative pressure waveforms in low-pressure cycling modes during the test period. 


\section{Limitations}

The infant mannikins used in this study were designed for simulating resuscitation with bag mask and endotracheal tube ventilation. The nasal orifices were not suitable for the application of nasal prongs. Consequently, treatment was delivered through an endotracheal tube. Future studies could quantify the effect of leaks at the nasal interface, which are relevant to all noninvasive modes of ventilation.

The current study is limited to a passive mechanical analysis demonstrating the consistency of airway pressure delivered to test lungs within infant mannikins. The mannikin does not make spontaneous respiratory efforts, cough, or "fight the ventilator." As a result, parameters such as tidal volume, interaction with spontaneous respirations, blood pressure variation, oxygen saturation, and blood gas analysis could not be assessed. The current study represents the first step in device development, documenting consistent delivery of pressures, which is a prerequisite to further clinical application.

\section{Essential Features to Address Neonatal Respiratory Distress}

For a device to have an impact globally in resource limited settings, it must be robust and reliable. Bubble CPAP has proven to be highly effective and has penetrated remote areas because of its low cost, simplicity of use, effectiveness, and low electrical power requirements. ${ }^{6}$ The technology we describe incorporates many of the same features and can be integrated seamlessly into an existing bubble CPAP delivery system. The technology is a simple mechanical device that is fully powered by the exhaust bubbles of bubble CPAP, requiring no electrical power. Family members and nurses noting the vertical oscillations of the device can verify adequate operation. In clinical practice, treatment could be delivered in which an infant is started on bubble CPAP and subsequently switched to bubble BPAP or bubble NIV if the condition does not improve. A child who is receiving bubble CPAP or BPAP can easily receive kangaroo care (direct skin to skin contact with the mother) with no interruption in airway support. This combination helps to further cement the bond between mother and child as contrasted with the isolation associated with placing the child on a mechanical ventilator and in an incubator.

\section{Conclusions}

Many resource-limited settings do not have the personnel, funds, or infrastructure to provide neonatal mechanical ventilation. In these settings, bubble CPAP has been successfully implemented, with survival rates near $70 \%$. Additional low-cost, low-tech treatments are necessary to save some of the remaining infants. This study demonstrates that 2 levels of pressure similar to BPAP and NIV modes can be reliably delivered over a prolonged period of time using a modified bubble CPAP circuit. These promising preclinical results represent the first step in validation of device function.

\section{ACKNOWLEDGMENTS}

We thank Dr Gary Weiner, who provided the neonatal mannikins used in the study, and Mr Peter Thannhauser, who developed the LabView continuous pressure recording system.

\section{REFERENCES}

1. Lawn JE, Cousens S, Zupan J, Lancet Neonatal Survival Steering Team. Neonatal survival 1: 4 million neonatal deaths: when? where? why? Lancet 2005;365(9462):891-900.

2. Martin S, Duke T, Davis P. Efficacy and safety of bubble CPAP in neonatal care in low and middle income countries: a systematic review. Arch Dis Child Fetal Neonatal Ed 2014;99(6):F495-F504.

3. Wilson PT, Morris MC, Biagas KV, Otupiri E, Moresky RT. A randomized clinical trial evaluating nasal continuous positive airway pressure for acute respiratory distress in a developing country. J Pediatr 2013;162(5):988-992.

4. van den Heuvel M, Blencowe H, Mittermayer K, Rylance S, Couperus A, Heikens GT, Bandsma RH. Introduction of bubble CPAP in a teaching hospital in Malawi. Ann Trop Paediatr 2011;31(1):59-65.

5. McAdams RM, Hedstrom AB, DiBlasi RM, Mant JE, Nyonyintono J, Otai $\mathrm{CD}$, et al. Implementation of bubble CPAP in a rural Ugandan neonatal ICU. Respir Care 2015;60(3):437-445.

6. Duke T. CPAP: a guide for clinicians in developing countries. Paediatrics and international child health 2014;34(1):3-11.

7. Kawaza K, Machen HE, Brown J, Mwanza Z, Iniguez S, Gest A, et al. Efficacy of a low-cost bubble CPAP system in treatment of respiratory distress in a neonatal ward in Malawi. PLoS One 2014;9(1): e86327.

8. Lee KS, Dunn MS, Fenwick M, Shennan AT. A comparison of underwater bubble continuous positive airway pressure with ventilatorderived continuous positive airway pressure in premature neonates ready for extubation. Biol Neonate 1998;73(2):69-75.

This article is approved for Continuing Respiratory Care Education credit. For information and to obtain your CRCE

(free to AARC members) visit

www.rcjournal.com

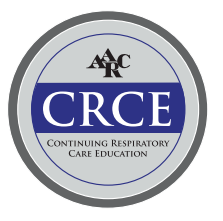

